\title{
Quando cinema e saúde se cruzam: o HIV/Aids em Yesterday
}

\author{
Esmael Alves de Oliveira ${ }^{1}$ \\ Universidade Federal da Grande Dourados \\ Eliciel Freire de Salles ${ }^{2}$ \\ Universidade Estadual de Mato Grosso do Sul
}

Resumo: O presente trabalho busca refletir sobre a intersecção entre cinema e saúde. Ao nos voltarmos para a análise do filme sul-africano "Yesterday" nos propomos pensar, numa perspectiva antropológica, em que medida a narrativa cinematográfica constrói significados sobre processos de adoecimento e, desse modo, reitera ou reelabora imaginários e compreensões em torno da problemática do HIV/Aids. Quais os discursos? Quais os sentidos? Quais possíveis as conexões entre a ficção e "realidade"? Como pensar a saúde a partir de uma perspectiva estético-cinematográfica? Seria possível uma antropologia da saúde a partir do cinema? São questões que buscaremos problematizar e refletir a partir dos principais aspectos que compõem a miseen-scène de Yesterday.

Palavras-chave: cinema, antropologia, corpo, HIV/Aids. 


\title{
When cinema and health intersect: HIV/AIDS in Yesterday
}

\begin{abstract}
This study aims to reflect on the intersection between cinema and health. When we turn to the analysis of the South African film Yesterday we propose thinking, an anthropological perspective, the extent to cinematic storytelling creates meaning about disease processes and thus repeats or reworks imaginary and understandings around the issue of HIV/Aids. Which discourses? Which way? What possible connections between fiction and "reality"? How To Think health from an aesthetic and cinematic perspective? Is it possible a health anthropology from the cinema? These are questions that seek to question and reflect from the main aspects that make up the mise-enscène of Yesterday.
\end{abstract}

Keywords: cinema, anthropology, body, HIV/AIDS.

\section{Cuando el cine y la salud se cruzan: VIH/SIDA en Yesterday Yesterday}

Resumen: Este estudio tiene como objetivo reflexionar sobre la intersección entre el cine y la salud. Cuando pasamos al análisis de la película sudafricana Yesterday proponemos pensar, una perspectiva antropológica, la medida en la narración cinematográfica crea significado sobre los procesos de enfermedad y por lo tanto se repite o retrabaja los imaginarios y la comprensión de todo el tema de la VIH/SIDA. ¿Qué discursos? ¿Qué camino? ¿Qué posible conexión entre la ficción y la "realidad"? Cómo Pensar la salud desde una perspectiva estética y cinematográfico? ¿Es posible una antropología de la salud desde el cine? Estas son preguntas que tratan de cuestionar y reflejan de los principales aspectos que conforman la mise-en-scène de Yesterday.

Palabras clave: cine, antropología, cuerpo, VIH/SIDA. 
A Antropologia tem se constituído enquanto um campo vasto de objetos, métodos e teorias. Se num primeiro momento suas reflexões voltaram-se para a busca pela compreensão de contextos geograficamente distantes, hoje o fazer antropológico é formado por uma multiplicidade de campos de atuação e reflexão (VELHO, 1978; PEIRANO, 1997; MARCUS, 2009). Nesse artigo, buscamos refletir sobre a relação entre antropologia e cinema. Para tal, voltamo-nos para a análise do filme sul-africano Yesterday. Por meio dele, nos propomos pensar, numa perspectiva antropológica, em que medida a narrativa cinematográfica constrói significados sobre processos de adoecimento e, desse modo, reitera ou reelabora imaginários e compreensões em torno da problemática do HIV/Aids. Quais os discursos? Quais os sentidos? Quais possíveis as conexões entre a ficção e "realidade"? Como pensar a saúde a partir de uma perspectiva estético-cinematográfica? Seria possível uma antropologia da saúde a partir do cinema? São questões que buscaremos problematizar e refletir a partir dos principais aspectos que compõem da mise-en-scène de "Yesterday".

Parece ser consensual entre os pesquisadores que o campo do que se convencionou chamar de Antropologia da Saúde é uma área consolidada enquanto um campo específico de investigação (ALVES E RABELO, 1998; LANGDON E WIIK, 2010; SARTI, 2010). A partir de diferentes perspectivas e abordagens e voltando-se para um leque variado de temas/objetos, os antropólogos que se "embrenham" nesse horizonte de pesquisa, são unânimes em afirmar o caráter histórico, simbólico e cultural dos processos de saúde, adoecimento, cura (LANGDON, 1994; SARTI, 2001). De um modo geral, essa construção social do corpo, e por consequência os processos de adoecimento e também os complexos terapêuticos, e os modos pelos quais os diferentes contextos culturais passam a significá-lo, mostram que a dimensão simbólica se constitui enquanto um campo significativo a ser investigado e problematizado e que, portanto, não pode ser ignorado. Ao longo da história da antropologia, observa-se uma variedade de abordagens que remetem a esse caráter construtivista e simbólico.

Robert Hertz, no texto a "Preeminência da mão direita" (1980), nos ajuda a compreender como a valorização que as sociedades humanas dão a certas partes do corpo, antes de mostrarem como um dado natural, estão inseridos em amplos processos de naturalização e construção de sentido. Nesse mesma esteira Marcel Mauss, em “As técnicas do corpo" (2003), afirma que o que consideramos como mais "natural" encontra sua razão de ser nos processos de socialização e, portanto, de educação do corpo. Nesse sentido, os atos mais corriqueiros como andar, sentar, correr etc., mais do que atos "mecânicos" são produtos da cultura. Além disso, há que se levar em conta os processos simbólicos que inserem o corpo em dimensões cosmológicas. O trabalho de Maurice Leenhardt (1961) entre os kanacs apontou a indivisibilidade, no pensamento melanésio, entre sujeito e seu corpo, entre o "eu" e a natureza circundante, entre os vivos e os mortos. Do mesmo modo, em contextos ameríndios, essa relação entre o sujeito e seu corpo não implicariam processos 
de dualidade e separação, mas à uma noção de um corpo fabricado que passa por processos contingentes e relacionais (SEEGER et al, 1979). 3

O que dizer também dos processos de adoecimento? Em que medida o orgânico e o cultural se relacionam e/ou se contrapõem? Haveria uma sobreposição de um sobre o outro? Ou seria possível pensar numa justaposição de sentidos?

\section{Quando o corpo/doença "vai" ao cinema....}

O foco de nossa análise volta-se para o filme Yesterday. O filme foi produzido em 2004, de autoria do cineasta sul-africano Darrell James Roodt. É um filme emblemático, pois traz à tona aspectos importantes da cultura local sul-africana e sua relação com a problemática do HIV/Aids na contemporaneidade. Como pensar essa problemática a partir do cinema? Que problemas aponta? Que questionamentos suscita?

Para início de conversa podemos dizer que é um filme metafórico (MARTIN, 2011). Além da temática central do filme - uma família afetada pelo HIV/Aids - as imagens por si mesmas também são bem provocadoras. É um filme de poucos diálogos, mas de muitas imagens. Imagens essas que relativizam o lugar do corpo transpassado pela experiência do HIV/Aids reiterado pelo discurso médico ocidental e nos permitem pensar e repensar sobre outras lógicas de construção de discurso e sentido.

Em se falando de metáforas, o nome da personagem se torna emblemático: Yesterday (em português - “ontem, passado, dia de ontem”). De fato, tanto o cenário onde se desenrola a trama (um vilarejo que se encontra há duas horas da área urbana da vila) quanto o drama vivenciado pela personagem principal (descobre ser portadora de HIV) remete à uma temporalidade pretérita, onde a força das tradições se impõe de modo preponderante e a luta da personagem principal pela sobrevivência não se faz sem tensões e sofrimento.

O filme conta a história de Yesterday Rooihoek, uma mulher pobre, porém determinada, que mora com sua filha Beauty, em um pequeno vilarejo de uma afastada comunidade rural sul-africana. Casada, passa a maior parte do tempo sozinha pois o marido trabalha nas minas de carvão em Johannesburg. O contato com o marido se dá esporadicamente nas visitas que o mesmo faz à família durante suas folgas. O filme inicia mostrando a longa jornada enfrentada por Yesterday em busca de atendimento/tratamento médico para tratar uma tosse persistente, que afeta o desenvolvimento de suas atividades cotidianas e que a deixa cada vez mais debilitada. Conforme a trama de desenrola, a situação de saúde de Yesterday piora ainda mais. São muitas idas e vindas. $O$ posto de saúde, estabelecido dentro de uma missão religiosa, não conta com uma estrutura adequada e nem com um contingente suficiente de médicos, e diante de um grande número de pessoas para serem atendidas, Yesterday acaba por não conseguir atendimento imediato. Isso acarreta o agravamento de seu estado de saúde. Após as muitas tentativas, consegue o atendimento e, depois de fazer um exame de sangue solicitado pela médica, acaba por descobrir que é portadora do HIV. A trama é cheia de percalços e tensões e a personagem vivencia momentos de grandes dificuldades. Apesar do cenário desolador em que se desenvolve a trama e do tema central da narrativa (o HIV/Aids em contextos rurais da África do Sul), a dedicação que Yesterday

3 Para uma discussão mais aprofundada sobre o lugar do corpo na tradição antropológica, consultar: Maluf (2001), Almeida (2004) 
tem para com sua filha Beauty e a esperança com relação a um futuro melhor para a mesma, não há espaço para uma perspectiva niilista.

O filme é rico em detalhes e nos permite elaborar uma série de questões que nos ajudam a compreender os complexos processos que envolvem a relação da sociedade com a problemática do HIV/Aids no mundo contemporâneo à partir de uma abordagem pouco convencional nos estudos que se voltam a esse tema. O que o cinema teria a nos falar sobre isso? Quais os horizontes de possibilidade analítico-reflexiva? Dentre um universo amplo de questões abordadas na narrativa, destacaríamos alguns pontos: a tensão entre o conhecimento local ("tradição") e o conhecimento ocidental ("modernidade") 4 e suas implicações, a clivagem entre o rural e o urbano e os processos daí advindos, as relações de gênero entre os sujeitos e suas condições de vulnerabilidade e, por fim, os diferentes imaginários sociais de significação sobre o HIV/Aids.

A "tensão" entre o conhecimento local e o conhecimento ocidental e o trânsito entre o rural e o urbano podem ser visualizados em vários momentos do filme. Antes de se constituírem como realidades estanques são interpenetrados por múltiplos diálogos e interações. Seja no momento em que se evidencia a precariedade da vila em que mora Yesterday em comparação com a capital (Johannesburg), seja no momento em que aparecem as diferentes lógicas de tratamento da "doença" da personagem principal (a curandeira da vila versus a médica da missão), põem-se em questão diferentes processos de agenciamento bem como a inter-relação entre diferentes contextos e seus respectivos contrastes. Nesse cenário, a apresentação de Johannesburg como uma cidade/capital desenvolvida e cosmopolita em contraposição à precariedade da realidade em que vive Yesterday em sua pequena vila mostra-se paradigmática. Tudo isso nos leva a refletir sobre os dilemas estruturais enfrentados pelos portadores de HIV em diferentes contextos socioculturais. Dificuldades essas que vão deste o acesso ao atendimento básico-inicial, e que visam o diagnóstico, até o acompanhamento especializado (o tratamento em si) e obtenção dos antiretrovirais.

Com relação a esse aspecto, há que se destacar que a África do Sul atualmente é um dos países de grande desenvolvimento em África. Johannesburg, capital, se configura como uma cidade cosmopolita e que, por este motivo, atrai a atenção e o interesse de sul-africanos de várias cidades/regiões do país bem como de estrangeiros. Com uma população de 48,6 milhões de pessoas (estimativa junho de 2013), uma composição populacional composta por vários grupos étnicos (zulus 20,5\%, chosas $18 \%$, pedis $9 \%$, sotos $7 \%$, tsuanas $6 \%$, tsongas $3,5 \%$, suazis $2 \%$, nedebeles $2 \%$, vendas $2 \%$ ) e por diferentes nacionalidades - europeus $12 \%$ (holandeses, alemães, franceses, ingleses), eurafricanos $13 \%$, indianos $3 \%$, outros $2 \%$ ) e uma economia centrada principalmente na mineração (carvão, minério de ferro, petróleo, ouro e diamante) e na indústria, a África do Sul apresenta uma realidade sociocultural rica e ao mesmo tempo complexa. E esta complexidade é bem apresentada em Yesterday a partir do contraste entre o grande centro e a realidade precarizada em que vive a personagem e sua filha.

4 Vale destacar que tais polaridades antes de significarem realidades absolutas e essenciais, se constituem apenas como estratégia analítica. Não podemos perder de vista as implicações mútuas de contextos e realidades (multilocalidade). A esse respeito, ver Bastos (2002). 
$\mathrm{Na}$ pequena vila, muito distante imponente da capital, predominam as relações de vizinhança, as práticas locais de cura (que tencionam com os tratamentos convencionais do sistema de saúde), o protagonismo feminino (tendo em vista o deslocamento dos homens para a capital a fim de trabalhar nas mineradoras e áreas afins) e uma série de questões que em muito falam de um lugar de esquecimento e dificuldades. Assim o urbano versus o rural, enquanto realidades geograficamente distantes, revelam outros distanciamentos: a capital como um lugar de oportunidade em contraposição à vila como um lugar de dificuldades. Esse contraste terá implicações no modo como a personagem viverá as agruras de sua soropositividade. Nesse cenário, a dificuldade inicial em obter o diagnóstico mostra-se como apenas um dos muitos dilemas a serem superados por Yesterday. Diante disso, como não pensar nas tensões existentes no próprio contexto em que vive a personagem, marcado por uma presença de relações sociais de vizinhança muito estreitas e de uma mentalidade conservadora? Como isso tem implicações no modo como os sujeitos dos diferentes contextos lidam com a doença? É marcante no início do filme o momento em que Yesterday, diante da dificuldade de conseguir consultar-se com a médica da missão, acaba por procurar, motivada pela sugestão de suas vizinhas, o tratamento convencional de sua comunidade: a curandeira. Ali receberá o diagnóstico de sofrer de problemas espirituais: sofre de "raiva" e é isso que está lhe adoecendo. Antes de reiterarmos um discurso ocidentalizante que tende a enxergar essas práticas como impregnadas de "obscurantismo" e ineficácia, cabe pensar essas questões numa perspectiva antropológica em que a compreensão dos contextos culturais não ocidentais ganham relevância e passam a ser encarados em sua complexidade. Diferentes autores na história da antropologia tem destacado a importância dos sistemas de feitiçaria/bruxaria como um importante elemento de construção simbólica e social no interior dos diferentes grupos étnicos africanos (EVANS-PRITCHARD, 2005; FRY, 2000; PASSADOR, 2011). Esse complexo simbólico muitas vezes tende a tensionar com os conhecimentos ocidentais, encarados pela perspectiva médica hegemônica como de pouco valor e eficácia. Nesse cenário, diante dos sintomas apresentados pela personagem, dois diagnósticos distintos: o sofrer de "raiva" (dado pela curandeira) e a infecção por HIV (dado pela médica da missão). Em evidência as tensões entre as práticas religiosas locais ("tradicionais") e o conhecimento médico ocidental. De nossa parte encaramos esse processo numa perspectiva cultural em que a doença é encarada como um “processo experiencial” (LANGDON, 1994) em que fatores culturais, sociais e psicológicos não podem ser ignorados.

Diante da dificuldade de conseguir o atendimento médico convencional, Yesterday procura a curandeira do vilarejo. Após a evocação do espírito dos antepassados, como diagnóstico é dito que a "doente" padece pois traz em seu interior "muita mágoa, muito remorso, muita raiva". De outro lado temos o parecer da médica da missão que, após exame clínico, informa à personagem que a mesma está com HIV. Múltiplos saberes, múltiplos olhares, enfim, muitos agenciamentos. Mas afinal de que se trata a "raiva" que a curandeira pede para Yesterday se livrar? Raiva das incompreensões sociais, raiva de si mesma, raiva 
das condições sociais à que está submetida, raiva diante da impotência que experimenta face aos dilemas que enfrenta? Em todos os cenários a experiência da corporalidade é fundamental, não podemos esquecer que é corpo é o lócus privilegiado de intervenção do conhecimento médico e também o lugar em que a cultura opera no sentido de imprimir seus códigos, preceitos, normas e também tabus.

Contudo, em nenhum momento da narrativa o autor elabora um discurso de privilégio de uma realidade sobre a outra. Pelo contrário, o tempo todo é possível visualizar a imbricada relação de complementaridade entre os contextos e as lógicas de significação. A vila se constitui nessa relação com a capital (Johannesburg) e mesmo o processo de adoecimento não escapa a essa justaposição. Embora não seja mostrado diretamente no filme como o marido de Yesterday contrai o HIV, dá a entender que sua condição de trabalhador (mineiro) a viver na capital oportunizou a situação de infecção. O que levou posteriormente a infectar sua esposa (que vivia na vila). Além disso, há toda uma "interação" entre sujeitos, conhecimentos, discursos e símbolos.

Outro aspecto a ser destacado são as relações de gênero vividas pela personagem. Não podemos ignorar o contexto cultural na qual a mesma se insere. As sociedades africanas, de um modo geral, e sul-africanas, de modo particular, terão recorrentemente em sua conformação cultural uma organização de parentesco centrada na figura masculina (sociedades patriarcais). É nesse contexto que vive Yesterday. De origem étnica zulu, a personagem em vários momentos transparece a tensões desse sistema de parentesco. Após ser diagnosticada pela médica de que é portadora de HIV vai até Johannesburg para contar o resultado do exame ao seu esposo. Lá se tornará vítima da ira do marido, que tenderá a acreditar que a infecção foi causada pela "infidelidade" de sua mulher. Na violência se evidência o imaginário de uma masculinidade que vê o corpo feminino como "perigoso", "poluidor" (DOUGLAS, 2012) e ao mesmo tempo o modo como as relações de gênero em contextos africanos está permeada pela sobreposição do masculino sobre o feminino. Ainda assim, não há espaço para vitimização. Yesterday mostra-se, diante dos dramas que vive, como protagonista da própria história, da própria vida. Ao tomar para si a responsabilidade de manter e educar a filha nos momentos de ausência paterna; ao assumir os "ônus" de seu adoecimento e ao persistir; ao se impor diante do preconceito da comunidade e buscar alternativas para superá-la, Yesterday fala de um lugar de um lugar resistência e não de subalternidade.

Esse protagonismo é visível quando seu marido volta de Johannesburg debilitado pela doença. Nesse momento, ao circular na vila a notícia de que o marido de Yesterday voltou da capital e que está gravemente doente, a família permanece num estado de situação liminar: todos viram as costas para a família e cobram o isolamento do doente para que não haja infecção dos comunitários. Diante do interdito coletivo, a personagem constrói sozinha um pequeno quarto num lugar afastado da vista da comunidade e lá cuida do marido gravemente enfermo até a morte do mesmo. Em cena a ideia de contaminação, de evitação, de interdito que geralmente cercam os processos de adoecimento no mundo social (DOUGLAS, 2012; POLLACK, 1990) e que apenas servem para culpabilizar e estigmatizar os sujeitos. Segundo esse imaginário, por via das dúvidas, melhor manter a distância. 
Apesar de toda dramaticidade, a narrativa não abre mão da poesia e singeleza. Yesterday é a metáfora de um "sujeito-corpo" que não se rende às determinações da realidade e circunstâncias em que vive. Seus dilemas poderiam ser comparados aos de outras "Yesterdays" que vivem o mesmo drama. Além disso, há uma série de outros protagonismos femininos que não passam despercebidos na trama: a falta de médicos não faz com que a médica da missão desista de sua profissão; a falta de atendimento não faz com que os pacientes deixem de tentar a consulta diariamente; a luta heroica e solitária de Yesterday na construção de um refúgio para o marido buscando desse modo contornar o preconceito da comunidade; a doença não impede que as pessoas percam a capacidade de sonhar ( Yesterday diz que o que a mantêm viva é o ingresso de sua filha na escola); a persistência das professoras que aparecem no início do filme a procura de emprego nos vilarejos, etc.

Há ainda outros elementos de esperança: apesar da situação incontornável da doença (seu estado de saúde é cada vez pior), Yesterday vê na filha a possibilidade de um futuro melhor. Poderíamos afirmar que, na filha, Yesterday vê a possibilidade de se imortalizar. Ao mesmo tempo, a grande quantidade de crianças no final da trama (personagens que não apareceram com tanta densidade ao longo do filme - senão em raros momentos) fala da esperança de um futuro melhor. Em que esses e outros dilemas possam ser superados. Nesse sentido, caberia pensarmos o sentido metafórico do nome da filha de Yesterday - Beauty (beleza, graça, perfeição). Assim, o autor sem precisar construir imagens e imaginários de uma África desolada pela Aids e sem perspectiva de futuro (reproduzindo assim estereotipias coloniais), desenvolve com sensibilidade e perspicácia um roteiro que nos permite ir além de um discurso vitimizador.

\section{Quando imagem e saúde se "cruzam"}

Alguns autores, ao se debruçarem sobre a compreensão dos processos de adoecimento e das terapias de cuidado/cura, têm apontado para a importância de se pensar e problematizar as imagens (SONTAG, 2007; TRONCA, 2000; OLIVEIRA, 2014) como importante ferramentas de compreensão dos imaginários sociais. Se por um lado é no corpo que se "manifesta" os sintomas das doenças (machas, emagrecimento, tumores, etc.), por outro é por meio de imagens que o conhecimento médico e as instituições de saúde irão atuar tanto no sentido de intervir (por exemplo, tomografia, raio $\mathrm{x}$, etc.) quanto de conscientizar (campanhas de prevenção - cartazes, banners, folders). Portanto, é por meio de uma "visualidade" que os imaginários, práticas e discursos sociais se constituirão como biopolítica do corpo.

O HIV/SIDA emerge na década de 1980 como um impacto nas sociedades ocidentais. Diante do otimismo científico e de um imaginário do bem estar social, o aparecimento súbito de uma "doença" que em pouco tempo levava à morte suas "vítimas", sem que nenhuma intervenção médica tivesse resultado/sucesso, era motivo de grande apreensão pela comunidade médica (SONTAG, 2007; BASTOS, 2002). Se num primeiro momento o HIV é compreendido como uma mutação do vírus da sífilis pesquisas intensas serão feitas para descobrir as causas "reais" da doença. Que doença é esta que ataca homens, brancos, de classe média e de orientação sexual homo? Nas palavras de Foucault, aos poucos ia se concretizando uma "política da vida". 
Já na década de 70, Susan Sontag escreve um pequeno livro intitulado "Doença como metáfora" (2007), na obra Sontag discutia como a doença na história do ocidente esteve intimamente ligada à criação de metáforas. Ao longo da obra, a autora vai destacando o caráter fantasioso, falacioso, estereotipado (mas nem por isso ineficaz) das representações sociais em torno das doenças. Ao tomar como foco de reflexão o modo como a tuberculose e o câncer foram sendo encarados ao longo do tempo, Sontag ressalta que o mistério e o medo foram as condições indispensáveis para que algumas doenças pudessem ser "adjetivadas" (2007: 53). Deste modo se evita o contato, o "falar sobre", cria-se, portanto, um "tabu".

Se num primeiro momento a tuberculose é temida, aos poucos passa a se integrar dentro de todo um sistema de representação social e o "desconhecido" e "perigoso" passa a ser "controlado" e "tratado". Por outro lado, esse universo do "desconhecido" e "temível”/“perigoso" não permanecerá por muito tempo desocupado: O HIV/Aids logo tomará assento nesse tribunal do saber médico. Portanto, Sontag (2007) nos ajuda a pensar que o processo de compreensão social sobre as doenças não é um dado natural, mas produto das relações de saber/poder que foram sendo estabelecidos e modificados ao longo do tempo. Desse modo, do incognoscível, tenebroso, inelutável, e, portanto, perigoso, passa-se para o conhecível, tratável, evitável. Para a autora, recorrentemente na compreensão social sobre os processos de adoecimento o caráter moral sobrepôs-se ao fatual.

\begin{abstract}
A ideia de que uma doença pode ser explicada apenas por uma variedade de causas é exatamente a característica da reflexão acerca de doenças cuja causa não é compreendida. E as doenças tidas como determinadas por múltiplas causas (ou seja, misteriosas) são aquelas com mais possibilidades de uso como metáforas para o que é visto como moral e socialmente errado (SONTAG, 2007: 55-56).
\end{abstract}

Com relação ao HIV/Aids foi exatamente isto que ocorreu. Nos primórdios de sua manifestação nos EUA e na Europa, logo após as primeiras pesquisas (nos EUA e França), associou-se imediatamente a doença como relativa a "grupos de risco": primeiramente aos homossexuais (vale lembrar que no inicialmente o HIV/SIDA será pejorativamente chamado de "peste gay"), logo depois às prostitutas e aos usuários de drogas injetáveis. Tal associação liga-se diretamente a estes aspectos moralizantes acerca da relação entre doença e os chamados "comportamentos de risco".

Em outra obra, publicada em 1989, "Aids como metáfora" (2007), Susan Sontag, continua a pensar a relação entre doença e metáfora, desta vez trazendo para o palco de reflexões a AIDS. Nesta segunda publicação, Sontag retoma a noção de metáfora, mas agora relacionando diretamente com a questão da Aids. Sua análise agora consiste em pensar os modos pelos quais algumas metáforas foram se constituindo e ao mesmo tempo criando toda uma significação acerca da doença. Assim, para a autora, a Aids oscilou entre muitas metaforizações (por exemplo, bélicas - "combate", "guerra", "inimigo", "vítima", "invasão"; calamitosas - peste, etc). Conforme Sontag, "A genealogia metafórica da AIDS é dupla: uma invasão e uma poluição" (2007: 90).

O que é interessante notar é que nesse processo de adjetivação da doença, o "Outro" (o estrangeiro/o de fora) é sempre onde está localizado o perigo, o contágio, a zona de interdição. Assim se criam os estereótipos, as discriminações, as segregações. Inicialmente associada aos homossexuais, posteriormente localizada como sendo uma epidemia vindo do continente 
africano, a Aids por muito tempo foi encarada (e alguns contextos ainda o é) como um fenômeno exterior (precisamente um inimigo) que precisa ser "combatido", "eliminado", "controlado", etc.

Ítalo Troca por sua vez, no livro As máscaras do medo (2000), a partir de um diálogo com a literatura, busca compreender as representações sociais sobre a lepra e sobre a Aids a partir de imagens literárias do século XIX e XX. Em sua análise, que busca o cruzamento entre o discurso estético e o discurso científico, destaca a importância do imaginário social na construção dos discursos de "verdade" sobre o corpo, sobre as doenças, sobre os doentes e de modo eles operam no sentido de invisibilizar e estigmatizar os sujeitos em situação de adoecimento.

E o que dizer do HIV/Aids no cinema? Vivemos em um contexto em que as imagens ocupam um lugar privilegiado: os mass media, os reality shows, os selfies, as câmeras de vigilância, etc. A partir disso, poderíamos dizer sem hesitação que a sociedade contemporânea é por excelência uma sociedade visual. Como produtos culturais essas imagens não estão deslocadas de sentidos, de intencionalidades (BARTHES, 1964). Revelam por outro lado, padrões de comportamento, imaginários de gênero, modelos de interação, etc.

Especificamente no campo das Ciências Sociais no Brasil, as imagens têm ganhado grande proeminência na análise dos fenômenos sociais. Em tais trabalhos o cinema deixa de ser apenas uma produção voltada para o "entretenimento" e passa a ser encarado e problematizado como construtor de imaginários sociais, ou seja, conceitos e pré-conceitos podem ser construídos e reiterados por meio do cinema. Como uma construção social, o cinema não apenas tende a privilegiar modelos hegemônicos como também naturalizá-los. Buscando questionar o lugar de alguns desses modelos, cientistas sociais à partir de diferentes campos voltam-se a pensar o que é o normal. O que é o patológico. Qual o espaço ocupado pelas relações e práticas socialmente compreendidas como "abjetas". No bojo dessas reflexões é que o trabalho da antropóloga Debora Breder (2015) por meio da análise da produção cinematográfica contemporânea busca pensar o significado atribuído pelo cinema às práticas consideradas "tabus", como o incesto entre irmãos (gemelidade). Teriam tais produções uma intenção de questionar as convenções sociais ou apenas repetir os padrões estabelecidos? Paloma Silva (2012), por sua vez, ao refletir acerca dos modelos de família presentes nos filmes hollywoodianos busca questionar os arranjos afetivo-conjugais ali presentes. Haveria espaço no cinema para os novos modelos de família? Para as novas conjugalidades? Ou apesar das intensas transformações no mundo social a partir da emergência de novas identidades e da mobilização política de grupos minoritários, ainda seria prevalecente uma ordem heteronormativa? Na esteira dessa reflexão Oliveira (2014) também destaca a importância de se pensar a relação entre imagens cinematográficas, doenças e significados. $\mathrm{O}$ autor, em sua tese de doutorado, ao debruçar-se sobre o HIV/Aids no cinema de Moçambique, buscou problematizar, a partir do cruzamento entre imagens e discursos, o modo como a epidemia é significada e apropriada pelos sujeitos e organismos sociais moçambicanos dando margem para múltiplos agenciamentos e desnaturalizações do discurso médico-taxonômico. Segundo o autor, à medida que essas imagens não estão descoladas de processos históricos e culturais, elas nos permitem pensar o modo como a sociedade se pensa, se organiza e constitui seus significados, valores e imaginários de seus sujeitos. 
É nessa perspectiva que buscamos compreender Yesterday. Como um produto cultural, suas imagens nos revelam uma série de questões e tensionamentos que nos ajudam a relativizar o lugar do corpo e do HIV/Aids na cultura ocidental. Dentro de um contexto em que operam múltiplas lógicas e agenciamentos, por meio de seus enquadramentos, discursos, campos e contracampos, o cinema também nos ajuda a deslocar nosso olhar para aspectos e questões até então pouco considerados pelo discurso médico ocidental. Por isso nossa intenção de pensar o corpo transpassado pela experiência do HIV/Aids como um espaço simbólico. Nesse cenário, as abordagens clássicas da antropologia em torno do corpo como uma construção social são apenas o primeiro passo. Em nossa compreensão a perspectiva de um corpo que permanece apenas como um "objeto" passivo no qual se impregna a cultura (espécie de reflexo) não dá conta de pensar os processos de agenciamento do próprio corpo. Alguns trabalhos etnográficos tem chamado a atenção para a necessidade de releitura de uma visão ontologizada do corpo e da corporalidade (VILLAÇA, 2005; LIMA, 2002; SEEGER et all, 1979). Segundo tais autores, não seria possível falar e pensar numa totalização do corpo, mas uma instabilidade que aponta para contextos e relações em que as noções de natureza e de cultura são relativizadas e, por vezes, questionadas. Nessa perspectiva, da qual comungamos, a posição dos sujeitos é a posição do ponto de vista e esse ponto de vista é fundamentalmente condicionado pela experiência corporal que nunca é previamente dada, mas que se constrói na relação, no cruzamento de perspectivas, na interface de experiências, no labirinto de diferentes normas e interdições. Portanto, se é o ponto de vista que nos ajuda a compreender os próprios sujeitos, acreditamos que o corpo também ajuda na configuração desse ponto de vista. Trata-se de um processo de mútua implicação em que o corpo ao mesmo tempo em que é significado também significa. Nestes termos a biologização da saúde é questionada. E a imagem cinematográfica, ao colocar em cena a justaposição entre real/imaginário, entre sujeitos/instituições, linguagens/práticas, serve justamente para questionar o lugar unilateral de que os processos de saúde/doença têm gozado no discurso ocidental ao se restringir às taxonomias médicas. Em tal taxonomia, saúde/doença são apenas processos orgânico-biológicos. Mas seria possível pensar em uma única experiência de adoecimento? Seriam essas experiências redutíveis ao biológico? Ou nem mesmo o biológico permanece "ileso" nesse processo de significação cultural? É o que acreditamos. Afinal, como nos aponta Jaqueline Ferreira, "A noção de saúde e doença é também uma construção social, pois o indivíduo é doente segundo a classificação de sua sociedade e de acordo com critérios e modalidades que ela fixa." (1994: 103).

Do mesmo modo que a experiência de vida da personagem Yesterday é perpassada por múltiplos espaços/discursos de significação, sua doença (a Aids) também o é. É um problema de ordem espiritual ou de ordem orgânicobiológica? É um problema da ordem individual ou coletiva? É uma questão apenas médica ou também social? Ao brincar com essas categorias e realidades, o filme nos provoca para pensarmos a partir de um horizonte descentrado. $\mathrm{O}$ espanto revelado pela personagem de que está infectada pelo vírus e seu olhar de "confusão", que parece revelar a postura de alguém que não sabe exatamente o grau de complexidade da situação que está vivendo, põe em evidência a condição liminar das representações sociais que ainda pairam sobre a epidemia. Principalmente em contextos locais/tradicionais, de pouco acesso ao discurso 
de saúde/prevenção dos grandes centros. Num horizonte de incertezas, inseguranças e desconhecimento em que vive Yesterday, o médico também se torna cultural - ainda que resista a situar-se nessa condição - pois perpassado por múltiplas variáveis que não apenas do conhecimento biomédico.

Conforme aponta Sérgio Carrara,

\begin{abstract}
O que os cientistas fazem em seus laboratórios (o que nós mesmos fazemos) não é certamente, como quer o cientismo vulgar, descobrir fenômenos que desde sempre estavam lá à sua espera. Eles constroem símbolos a partir de certos materiais. E a relação entre os símbolos e a realidade que buscam exprimir não é nem totalmente aleatória, nem totalmente arbitrária. A questão certamente não é saber se o "vírus" existe lá antes de qualquer olhar curioso, mas se, a partir do momento em que ele se transforma em símbolo da doença com a qual ele foi construído, ele tem poder explicativo e é eficiente para orientar uma intervenção eficaz. Ele é um artefato biológico, foi feito pelos cientistas como todos os outros artefatos humanos, da roda ao computador (1994: 43).
\end{abstract}

Portanto, há que se levar em conta também a "relativização" do jargão médico, com relação aos projetos de saúde/prevenção, por parte dos sujeitos que encontram no nível das relações sociais outros processos de significação e apropriação que não os "politicamente corretos". Isso fica evidenciado quando Yesterday fica sabendo de sua condição sorológica e se dirige até a capital (Johannesburg) para contar ao marido. Na cena, não apenas torna-se vítima da violência do mesmo, como também passa a ocupar o lugar de suspeição. Naquela altura não há reconhecimento por parte do marido em reconhecer que possivelmente suas "aventuras" sexuais na capital (algo que fica apenas implícito na narrativa) é que sejam responsáveis pela infecção da esposa e não o contrário. A fidelidade matrimonial e a distância das situações de "risco"? Ou as aventuras extraconjugais e o "risco" de infecção? O que predomina? O desejo ou a norma? Isso nos permite pensar nas lógicas de significação presentes nas ações dos sujeitos em relação às "práticas de risco". Mas o que é o risco? Seria possível uma definição precisa tendo em vista a diversidade de posicionalidades dos sujeitos frente às diversas situações? Não haveria uma naturalização da noção de "risco" pelo conhecimento médico-científico? Nos cenários em que predominam "situações de risco", como posicionam-se os sujeitos? Em nossa perspectiva o risco, assim como as noções de corpo, saúde, doença, também é uma categoria sociocultural (DOUGLAS, 1994; JEOLÁS, 2003; OLIVEIRA, 2014) e entrelaçam-se com situações e posicionamentos subjetivos e intersubjetivos vividos pelos sujeitos e que não podem ser pré-captados e prédeterminados ao não ser no fluxo das próprias interações. Em que pese as tentativas de um discurso do "controle" e do "cuidado", presente nas iniciativas das instituições e organizações de saúde, e que passam por uma lógica de uma ação calculada, racional e autônoma e, consequentemente, "segura", os sujeitos também estão inseridos numa lógica de imprevisibilidade e situacionalidade, que andam de mãos dadas com afetos, desejos, paixões, interesses, que escapam a essas lógicas normativas do discurso preventivo e medicalizante (OLIVEIRA, 2014, JEOLÁS, 2003).

Desse modo, pensar o corpo a partir da relação saúde/doença, bem como os complexos processos terapêuticos a ele associados, nos permitem pensá-lo não apenas como objeto da cultura - sobre o qual incidem significados - , mas como produtor de múltiplos sentidos. O que aponta para uma dimensão corporificada da experiência e da construção da pessoa e dos modos que a mesma significa os processos de adoecimento e de cura. O Assim sendo, o desenrolar da trama presente em Yesterday nos permite analiticamente pôr em 
suspensão as polaridades essencializantes presentes no discurso médicocientífico ocidental, que tende a perceber as práticas dos sujeitos apenas numa relação de legalidade/ilegalidade, permitido/proibido, lícito/ilícito, normal/patológico. A pesquisa antropológica voltada para a análise do imaginário e da prática social em torno do HIV/Aids tem demonstrado que o usar ou não usar o preservativo, fazer ou não fazer sexo e estar condicionado as "situações de risco" apresentam questões que vão muito além do mero discurso médico-preventivo. Trata-se, principalmente, de complexos processos de construção de sujeitos, subjetividades e relações que quase sempre escapam à racionalidade cartesiana, ou que a ela se contrapõe, e que, por essa razão, nos ajudam a relativizar noções estanques como saúde e risco.

A partir de tudo o que foi exposto, acreditamos que pensar uma antropologia da saúde a partir do cinema se constitui não apenas como uma possibilidade metodológica mas também como um desafio aos cientistas sociais, inegavelmente inseridos numa sociedade visual. Se como afirma Cynthia Sarti, "fenômenos sociais e culturais - como qualquer fenômeno humano -, o corpo e a doença, assim como a dor e o sofrimento, constituem objetos de pesquisa que atravessam fronteiras disciplinares" (2010: 77), o que a linguagem cinematográfica, enquanto campo discursivo, teria a nos dizer sobre esses processos? Em que medida essa linguagem - atravessada por imaginários, discursividades e intencionalidades e construtora de sentidos - , reitera ou questiona as normas socialmente estabelecidas? Nos filmes que abordam processos de saúde/doença, haveria espaço para a subversão e o questionamento do maniqueísmo logocêntrico ocidental estabelecido pelo conhecimento médico-científico? Talvez nossa proposta de análise de Yesterday seja encarada por alguns como mera divagação estética e, consequentemente, de que não se trata de uma "verdadeira" reflexão antropológica. Porém acreditamos que o cinema, enquanto complexo cultural, pode fornecer pistas importantes de reflexão e compreensão dos imaginários e das práticas sociais em relação aos diversos fenômenos humanos - a saúde não seria um desses aspectos? Afinal não são sobre essas questões que a Antropologia tem se desafiado a pensar desde os seus primórdios?

\section{Referências}

ALMEIDA, Miguel Vale de Almeida. O corpo na teoria antropológica. Revista de Comunicação e Linguagens, 33: 49-66, 2004.

ALVES, Paulo César; RABELO, Miriam Cristina (Orgs.). Antropologia da saúde: traçando identidade e explorando fronteiras. Rio de Janeiro: Editora FIOCRUZ; Rio de Janeiro: Editora Relume Dumará, 1998.

BARTHES, Roland. La rethorique de l'image. Communication, n. 4, 1964. p.4051.

BASTOS, Cristiana. Ciência, poder, acção: as respostas à Sida. Lisboa: Imprensa de Ciências Sociais/Instituto de Ciências Sociais da Universidade de Lisboa, 2002. 
BREDER, Debora. "A Zed and Two Noughts: sobre antropologia, cinema e outras maquinações”. In: OLIVEIRA, Esmael Alves de; VIANA JÚNIOR, Mário Martins; COSTA, Patrícia Salvador Moura. Metodologias de Pesquisa em Ciências Humanas: Campos, problemas e objetos. Curitiba: CRV, 2015.

CARRARA, Sérgio. Entre cientistas e bruxos - ensaio sobre dilemas e perspectivas da análise antropológica da doença. ALVES, Paulo César; MINAYO, Maria Cecília de Souza (Orgs). Saúde e Doença - um olhar antropológico. Rio de Janeiro: FIOCRUZ, 1994.

DOUGLAS, Mary. Pureza e perigo. 2 ed. São Paulo: Perspectiva, 2012.

DOUGLAS, Mary. Risk and Blame: essays in cultural theory. Londres: Routledge, 1994.

FERREIRA, Jaqueline. “O corpo sígnico”. ALVES, Paulo César; MINAYO, Maria Cecília de Souza (Orgs). Saúde e Doença - um olhar antropológico. Rio de Janeiro: FIOCRUZ, 1994.

FRY, Peter. O Espírito Santo contra o feitiço e os espíritos revoltados: "civilização" e "tradição" em Moçambique. Mana [online]. 200o, vol.6, n.2, p. 65-95.

HERTZ, Robert. A preeminência da mão direita: um estudo sobre as polaridades religiosas. Revista Religião e Sociedade, v. 6, 1980. p. 99-128.

JEOLÁS, Leila. Os Jovens e o Imaginário da Aids: notas para uma construção social do risco. Campos 4:93-112, 2003.

LANGDON, Esther Jean; WIIK, Flávio Braune. Antropologia, saúde e doença: uma introdução ao conceito de cultura aplicado às ciências da saúde. Rev. Latino-Am. Enfermagem 18(3), mai-jun, 2010. p. 173-181.

LANGDON, Esther Jean. Representações de doença e itinerário terapêutico dos Siona da Amazônia colombiana. In: SANTOS, R.V.; COIMBRA JR, C.E.A. (Orgs). Saúde e povos indígenas. Rio de Janeiro: Editora Fiocruz, 1994. p. 115141.

LEENHARDT, Maurice. "Estructura de la persona em el mundo melanésio". In: Do Kamo. Buenos Aires: Eudeba, 1961.

LIMA, Tânia S. O que é um corpo? Religião e Sociedade, 22, 9-19, 2002.

MARCUS, George E. "A estética contemporânea do trabalho de campo na arte e na antropologia: experiências em colaboração e intervenção”. In: BARBOSA, Andréa; CUNHA, Edgar Teodoro; HIKIJI, Rose Satiko Gitirana (orgs.). Imagem-Conhecimento: Antropologia, cinema e outros diálogos. Campinas: Papirus, 2009.

MALUF, Sônia Weidner. Corpo e corporalidade: abordagens antropológicas. Esboços. PPGH/UFSC, v. 9, 2001, 87-101. 
MARTIN, Marcel. A linguagem cinematográfica. 2 ed. São Paulo: Braziliense, 2011.

MAUSS, Marcel. “As técnicas do corpo”. In: Sociologia e antropologia. São Paulo: Cosac \& Naify, 2003, p. 401 a 422.

OLIVEIRA, Esmael Alves de. Qualquer semelhança não é mera coincidência: Uma análise do HIV/Aids no cinema moçambicano. Tese de Doutorado defendida no Programa de Pós-Graduação em Antropologia Social da Universidade Federal de Santa Catarina. Florianópolis: PPGAS/UFSC, SC, 2014. 264 p.

PASSADOR, Luiz Henrique. Guerrear, casar, pacificar, curar: o universo "tradição" e a experiência com o HIV/Aids no distrito de Hemoíne, sul de Moçambique. 2011. Tese de doutorado apresentada ao Programa de PósGraduação em Antropologia Social da UNICAMP. Campinas: UNICAMP, 2011.

PEIRANO, Mariza. Onde está a Antropologia? Mana, 3 (2):67-102, 1997.

POLLAK, Michael. Os Homossexuais e a Aids: Sociologia de uma Epidemia. São Paulo: Estação Liberdade, 1990.

SARTI, Cinthia. Corpo e doença no trânsito dos saberes. Revista Brasileira de Ciências Sociais, 74, outubro, 2010.

SARTI,Cyntia. A dor, o individuo e a cultura. Revista Saúde e Sociedade, v.10, $\mathrm{n}^{0} 1$, jan - jul/2001.

SEEGER, A., DA MATTA, R. e VIVEIROS DE CASTRO, E. A construção da Pessoa nas sociedades indígenas brasileiras. Boletim do Museu Nacional, 32. Rio de janeiro: Museu Nacional. maio 1979, p.2-19.

SILVA, Paloma Ferreira Coelho. “OLHE BEM DE PERTO”: a construção dos discursos sobre a família nos filmes hollywoodianos contemporâneos. Dissertação de Mestrado defendida no Programa de Pós-Graduação em Ciências Sociais da Pontifícia Universidade Católica de Minas Gerais. Belo Horizonte: Programa de Pós-Graduação em Ciências Sociais, 2012. 210p.

SONTAG, Susan. "Doença e suas metáforas". "Aids e suas metáforas”. São Paulo: Companhia das Letras, 2007.

TRONCA, Ítalo. As máscaras do medo: LeprAids. São Paulo: Editora da Unicamp, 2000.

VELHO, Gilberto. “Observando o familiar". In: NUNES, Edson de Oliveira (Org). A aventura sociológica. Rio de Janeiro: Zahar, 1978.

VILLAÇA, Aparecida. Chronically unstable bodies. Journal of the Royal Anthropological Institute, 11, 2005. p. 445-464. 
ACENO, Vol. 2, N. 3, p. 93-108. Jan. a Jul. de 2015. ISSN: 2358-5587.

Políticas e Poéticas do Audiovisual na contemporaneidade: por uma antropologia do cinema (dossiê) 